\title{
A method for determining the suitability of schools as evacuation shelters and aid distribution hubs following disasters: case study from Cagayan de Oro, Philippines
}

\author{
Alexandra Tsioulou ${ }^{1}$ D . Joanna Faure Walker ${ }^{2} \cdot$ Dexter Sumaylo Lo $^{3} \cdot$ Rebekah Yore $^{2}$
}

Received: 18 March 2020 / Accepted: 12 October 2020 / Published online: 21 October 2020

(C) The Author(s) 2020

\begin{abstract}
Despite the controversy regarding their use, school buildings are often assigned as emergency evacuation shelters, temporary accommodation and aid distribution hubs following disasters. This paper presents a methodology to compare the relative suitability of different school buildings for these purposes by using the analytical hierarchy process to weight criteria based on the combined opinions of relevant experts and combine these with descriptive scores from surveyed buildings. The aggregated weights show that approximately equal weighting should be given to the hard characteristics (hazard at location and physical vulnerability) and soft characteristics (accessibility, communications, living environment, access to supplies). As well as immediate safety, conditions for inhabitation are important so that displaced persons are not discouraged from evacuating to shelters and shelter life is not detrimental to health and well-being. The study allows an optimal selection of school buildings used as shelters before and after a disaster and highlights where most improvement could be made with relatively little time and resources for both individual buildings and the whole study area. This method was applied to Cagayan de Oro in the Philippines, an area exposed to floods, windstorms and earthquakes, but can be adapted for other local contexts and building types. Among the 38 school buildings surveyed, we identified key areas for improvement as being insufficient pedestrian access for evacuation at night and for those with mobility constraints, and a lack of alternate spaces for evacuee activities leading to interference with education.
\end{abstract}

Keywords Vulnerability $\cdot$ Shelter $\cdot$ Distribution hub $\cdot$ Evacuation $\cdot$ Schools $\cdot$ Analytical hierarchy process

Electronic supplementary material The online version of this article (https://doi.org/10.1007/s1106 9-020-04380-3) contains supplementary material, which is available to authorized users.

Alexandra Tsioulou

alexandra.tsioulou@willistowerswatson.com

1 Willis Towers Watson, London, UK

2 Institute for Risk and Disaster Reduction, University College London, London, UK

3 Engineering Resource Center, Xavier University, Cagayan de Oro, Philippines 


\section{Introduction}

Adequate shelter in the post-disaster environment is an essential component of survival, safety and security, needed for protection from the weather, illness and disease, and supports the resumption of a sense of normalcy that can lead into early recovery processes (Felix et al. 2013). To serve this purpose effectively, emergency shelters must be accessible to those in need and provide suitable conditions once people arrive; shelter cannot just be thought of as the physical building, but the living conditions it provides (e.g. Faure Walker and Crawford 2017). Suitable accessibility, needed to encourage evacuation, includes the shelters being easy to find and being perceived as reachable, taking also into account those with reduced mobility or disability. For example, lack of awareness of evacuation shelter locations and the shelters being located at too great a distance from homes were cited by some residents as a deterrent for evacuation following the 2011 Great East Japan Earthquake and Tsunami (Naylor et al. 2018). Acceptable levels of quality of life include elements such as sufficient space, resource provision, privacy, the supply of clean water, sanitation facilities, and sanitary means of waste disposal and management to avoid the spread of infectious diseases in the shelters (McPherson et al. 2015; Surmieda et al. 1992). The World Health Organisation (WHO) report in response to Typhoon Haiyan (Yolanda) in the Philippines highlighted the significance of safe location, adequate sanitation services and an evacuee registration process provided by the shelter (McPherson et al. 2015); some residents reported both designated and unofficial shelters as lacking in various types of suitability for even relatively temporary habitation, a problem also found following 2017 Hurricane Maria in Dominica (Yore and Faure Walker 2020). The shelters suffered damage themselves, or failed to provide the safety and security needed, had no provisions for the storage of adequate supplies or were routinely overcrowded offering no real living space or privacy and therefore deterred people from using them (Yore and Faure Walker 2020).

International and national guidelines for emergency shelters consider key indicators relating to location and settlement planning, living space provided, household items, technical assistance, security of tenure and environmental sustainability (for example, the UN Shelter Cluster, FEMA, The Sphere Project, UK Government). The right to adequate shelter supporting the health and dignity of displaced persons encompasses the right to water supplies, adequate sanitation, food and health with resources to cook, eat and store food to meet nutritional requirements (The Sphere Project 2012; Sphere Association 2018). Similarly, FEMA guiding documents for general population shelters (FEMA 2010) discuss the need for medical first aid areas, sleeping, eating, passenger drop-off and pickup, recreational and quiet areas, and the need for accessible bathing and toileting facilities for children and adults. The UK Government Evacuation and shelter guidance notes health and safety, fire and security, telephone and internet access (crucial for responders to communicate between centres and organise evacuation), power supply, the provision of storage of basic supplies such as food, camp-beds and blankets, catering facilities that meet food hygiene standards and adequate parking facilities to be used by evacuees need consideration when deciding which buildings should be used for temporary shelters (HM Government 2014). These guidelines emphasise that proximity of the shelters to the evacuees' original area of residence makes the return to employment easier, maintaining ties to the local community. They also highlight the need for additional support such as access and facilities for people with disabilities (HM Government 2014).

There is a long tradition of using schools as officially designated evacuation centres, advised by authorities, as unofficial shelters in the Philippines and throughout the Pacific 
and Indian subcontinent and as aid distribution hubs where supplies are delivered, sorted and distributed to those in need (Asia Pacific Coalition for School Safety 2017). The majority of evacuation centres in areas impacted by Typhoon Haiyan in the Philippines were located in schools (Ramos et al. 2015), while in 2011, 89\% of all public schools in Japan were allocated as evacuation sites (National Institute for Educational Policy Research 2011). School buildings are considered safe and convenient because they are often built to good building standards, have a high degree of visibility and familiarity, and should be widely accessible to all.

Using schools as emergency and longer-term shelters, as well as aid distribution hubs, has been criticised due to potential negative impacts on education and employment (Luna et al. 2008; Rognerud 2009; Wang 2016). This is especially true of longer-term shelter use; however, it remains common for emergency evacuation centres to be used as shelters for longer than initially planned by authorities and communities. In Japan, 6 months after the 2011 Great East Japan earthquake and tsunami, community members could still be found sheltering in school buildings (Shaw and Takeuchi 2012a, b). In Fiji, following Cyclone Winston in 2016, 103 schools were used as evacuation centres affecting over 60,000 students (Asia Pacific Coalition for School Safety 2017). In the Philippines, cases where entire schools continued to be used as shelters for prolonged periods following disasters led to classes being conducted in tents within the school grounds (Luna et al. 2008). Over time this can increase student drop-out rates and staff unemployment, cause damage to school buildings and education materials, cleanliness issues and increase the exposure of school children to abuse, neglect and exploitation (World Bank 2010). This has given rise to more urgent calls from policy makers and field practitioners for better guidance (Asia Pacific Coalition for School Safety 2017). If a school has not been explicitly designed and prepared as an evacuation centre, damage and inadequate conditions can put sheltering populations at considerable risk. Authorities and response agencies must consider how emergency and transitional shelter options can be developed to form suitable refuges into longer-term recovery and reconstruction phases (Global Facility for Disaster Reduction and Recovery (GFDRR) 2011), bearing in mind the potential for disruption to education.

In an effort to reduce the negative educational impacts of school-based shelters, in 2016 Save the Children spearheaded the collaborative drafting of a number of guiding principles based on research and global shelter standards (Asia Pacific Coalition for School Safety 2017). The project was aligned with the Comprehensive School Safety Framework (CSS) formulated by the Global Alliance for Disaster Risk Reduction and Resilience in the Education Sector (GADRRRES) and United Nations Office for Disaster Risk Reduction (UNDRR). While some schools in areas of Bangladesh, India, Philippines, Japan and the USA have been specifically designed to include additional shelter facilities to serve as community evacuation centres (Shaw and Takeuchi 2012a, b; Shaw et al. 2012) as of 2017, only around half of Japanese public schools designated as emergency shelters had the ability to provide alternative toilet facilities if water supplies were cut off, and only $53.4 \%$ had their own power-generating facilities (The Japan Times, 2017). More encouragingly, $72 \%$ of schools surveyed in Japan had facilities to store relief supplies and $66 \%$ were able to secure drinking water in tanks or bottles (The Japan Times 2017). Furthermore, of the schools useable by the elderly and disabled, $62 \%$ had made their facilities more accessible, for example, by installing ramps (The Japan Times 2017).

Despite international standards and recommendations for improvements in the use of schools as evacuation centres, crucially lacking are guidelines for how to prioritise criteria within a structured assessment framework specifically designed to evaluate the relative suitability of community-based buildings such as schools. Relative vulnerability indices are 
often based on comparison matrices, such as PVTA for tsunami vulnerability (Dall'Osso et al. 2009). The indices can be based on observations of past events and expert judgment, and importantly can examine the physical vulnerability of structures and a wide range of criteria for assessing the relative suitability to often prolonged human habitation. Such a framework can identify possible modifications in the short and longer terms to improve the buildings for this purpose. Challenges in solidifying such frameworks arise as lessons learned aimed at practitioners are often confined to grey literature via field studies produced by shelter organisations and a relatively small number of academic articles and evaluation reports (Rohwerder 2016). This can lead to a lack of clarity over what acceptable shelter quality actually means within the response community, with problems compounded by inconsistent staffing, the frequent entry into the post-disaster environment of new and inexperienced actors unfamiliar with contextual idiosyncrasies, and "inconsistencies in terminology, approach and interpretation" (Da Silva 2007).

In this paper, we develop relative suitability indices for use of school buildings as evacuation shelters and aid distribution hubs. We combine the qualitative judgment of a selection of experts from a diverse range of disciplines and aggregate their opinions through the analytical hierarchy process (AHP). We provide a table of weightings for different factors and test bias in the results by comparing the calculated factor weightings between those from different sectors. We further provide a scoring system for each factor that is customised to our case study area, Cagayan de Oro, in the Philippines. We then demonstrate the applicability of our system through a set of example school buildings.

\section{Background to case study}

The Philippines is one of the most natural hazard-prone countries in the world, due to its location within the typhoon belt and along the Pacific Ring of Fire, where $80 \%$ of the world's earthquakes occur. Annually, an average of twenty tropical cyclones are experienced, with approximately eight or nine making landfall. Over the last 10 years, tropical storms in the Philippines have become more frequent and more severe (CFE-DMHA 2018).

Cagayan de Oro, located along the north central coast of the island of Mindanao, in the south of the Philippines (Fig. 1), is exposed to multiple hazards (tropical storms, floods and earthquakes). According to the city's Comprehensive Land Use Plan, 54 of the 80 barangays (villages) are considered as flood-prone areas, and 25 barangays are susceptible to rain-induced landslide (Local Government of Cagayan de Oro City, 2019). The city has been affected by recent floods following tropical storm Sendong (Washi, December 2011), typhoon Pablo (Bopha, December 2012) and tropical storm Vinta (Tembin, December 2017).

Cagayan de Oro is currently experiencing rapid commercial, residential, industrial and education facility expansion. It is an economic hotspot linking the agro-based products of neighbouring provinces to the country's central economic institutions in metropolitan cities like Manila, Cebu and overseas. It is a regional centre for education, having been awarded the Seal of Good Education Governance for last 3 years (2017-2019) (Orias 2019). Under the current local administration, more than 700 public school classrooms in almost 20 campuses have been built since 2013 .

As is broadly the case across the Philippines, schools are used as secondary evacuation shelters in Cagayan de Oro. During the Washi, Bopha and Tembin floods, 13, 11 and 16 


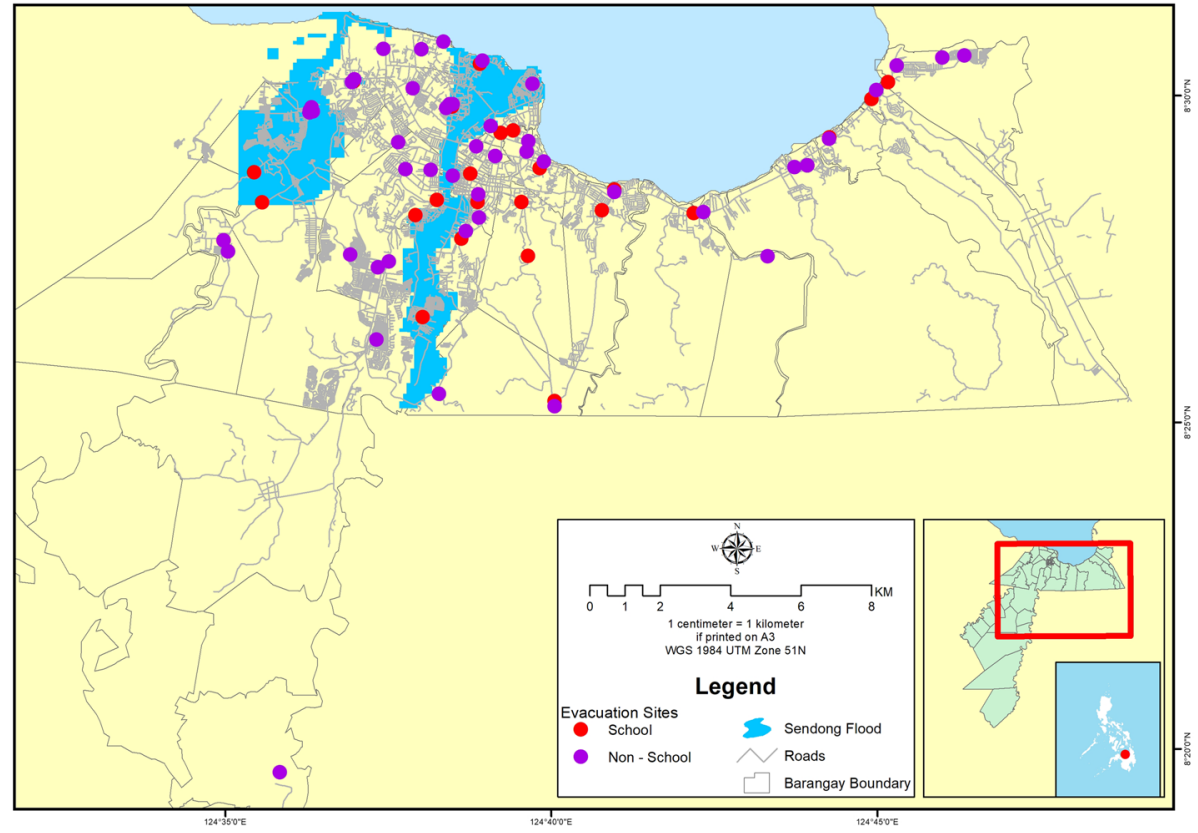

Fig. 1 Map of sites used as evacuation shelters within Cagayan De Oro in the Philippines during 3 recent flood events caused by tropical storms Sendong (2011), Pablo (2012) and Vinta (2017). The map shows the location of Cagayan de Oro within the Philippines and differentiates between school and non-school buildings used as shelters. The map is overlaid with the flood footprint of tropical storm Sendong (2011)

school campuses (as shown in Fig. 1) were used as official evacuation sites to house evacuating populations. Within the city, schools are not used as centralised distribution hubs, as relief goods are sorted at the City Social Welfare and Development (CSWD) office and then delivered to school campuses being used as evacuation sites.

\section{Methodology}

\subsection{Summary}

Criteria to be included for our relative suitability ratings were decided through a review of government and NGO guidelines, current academic literature, grey literature and consultation with field experts including NGO practitioners. Online surveys were sent to participants with relevant expertise, who were asked to rate the relative importance of the different parameters. The results from the participants were combined and the relative weightings of the different factors were determined through the analytical hierarchy process. Sensitivity tests were carried out to check data consistency and variations between those from different sectors. We developed the scoring for different criteria according to the local context and conducted fieldwork to assess selected school buildings against these criteria. We combined these scores with the weightings, to create relative suitability scores for the school buildings sampled. Figure 2 summarises the methodology adopted. 


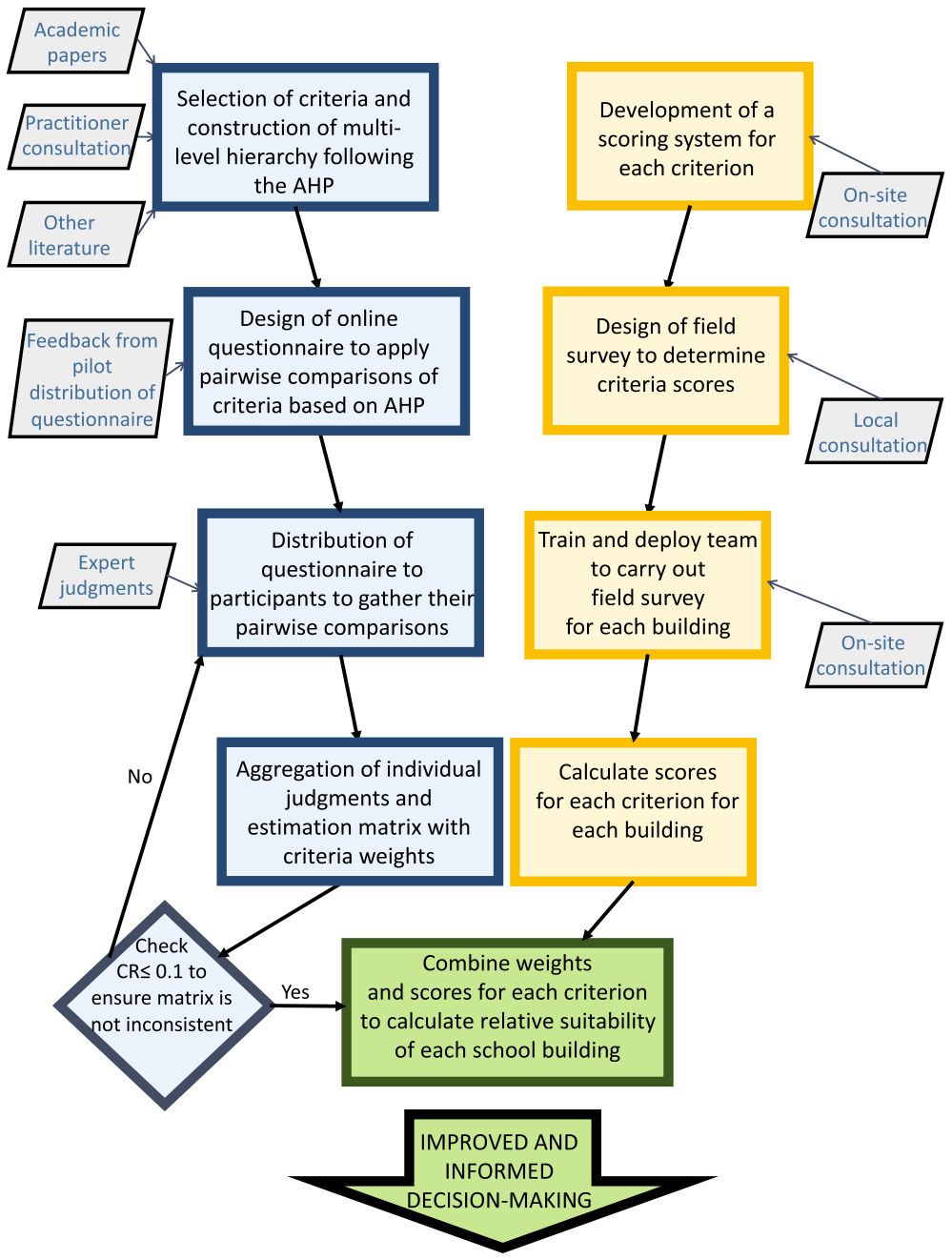

Fig. 2 Overview of the methodology adopted in the paper. Note that the methodology is generalised and can be used in other contexts

\subsection{Analytical hierarchy process (AHP)—calculation of weights}

The analytic hierarchy process (AHP) is an effective tool for dealing with complex decision-making, and may aid in setting priorities and making the best decision (Saaty 1980). It helps to capture both the subjective and objective aspects of a decision. This is achieved through reducing complex decisions to a series of pairwise comparisons, and then synthesising the results.

The essential component of all multi-criteria decision-making methods is the selection of a weight for each criterion that reflects the relative importance of it with respect to the others. A multi-level hierarchy for the goal and different criteria was constructed separately for the evacuation shelter and hub as shown in Fig. 3a and b, respectively. The first level of the hierarchy consists of the main criteria, i.e. hazard at location, physical vulnerability, 


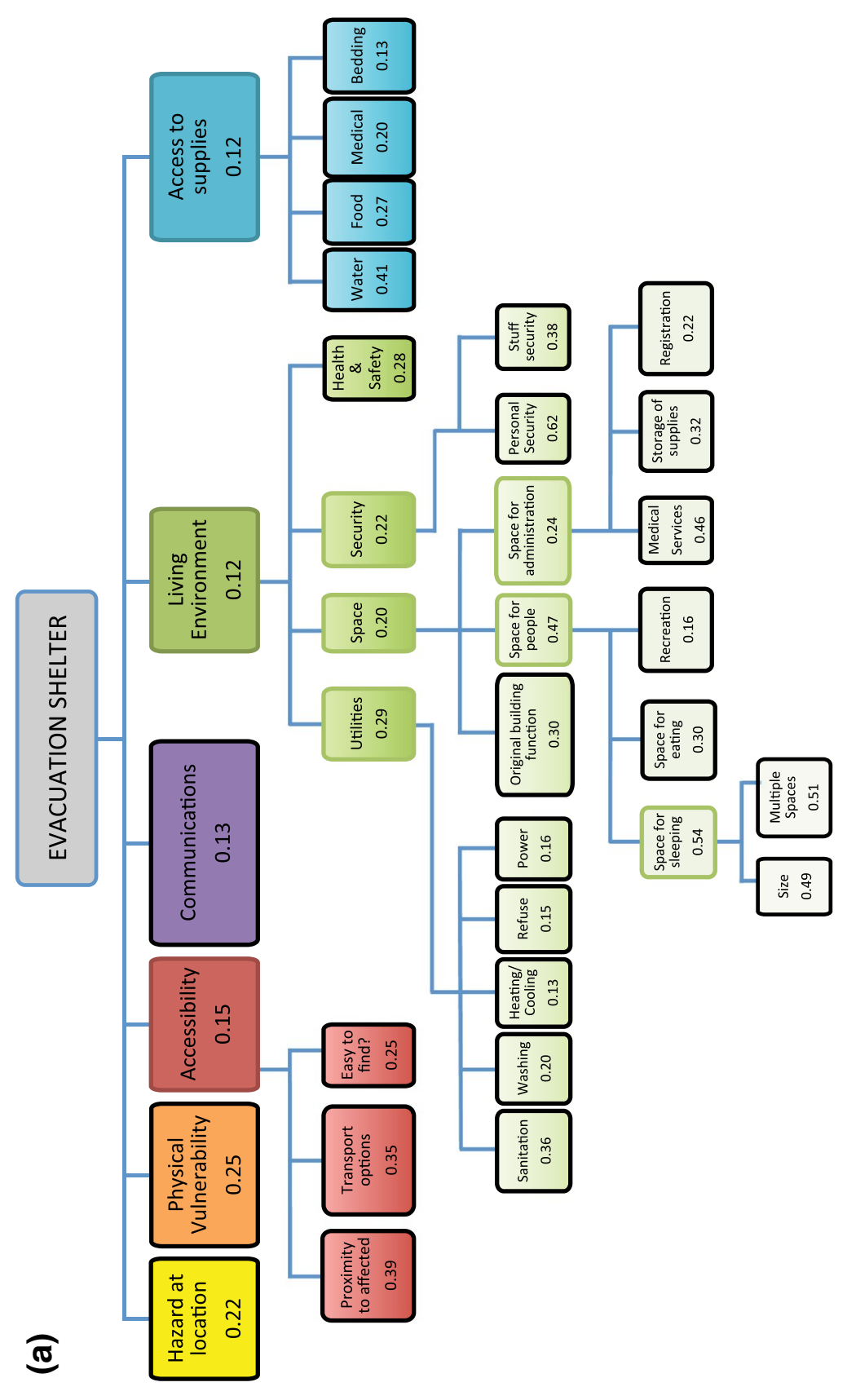

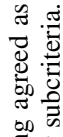

:

吅

过

की

䨠

on

$\stackrel{\Xi}{\Xi}$

莺

홍

密

콩

름

$\stackrel{\frac{\pi}{m}}{\Xi}$

z

䒠

ฮิ อ

害

疍

귤

ส

$\therefore$

寻光

Ð

过

흐을

흠 믈

ठ용

ठे.

ส

*

오응

를

एँ

Ð

氙

券

入

氙

흘

o क क

उ 3

U 氖

m

ㅇํㄴ. 局 


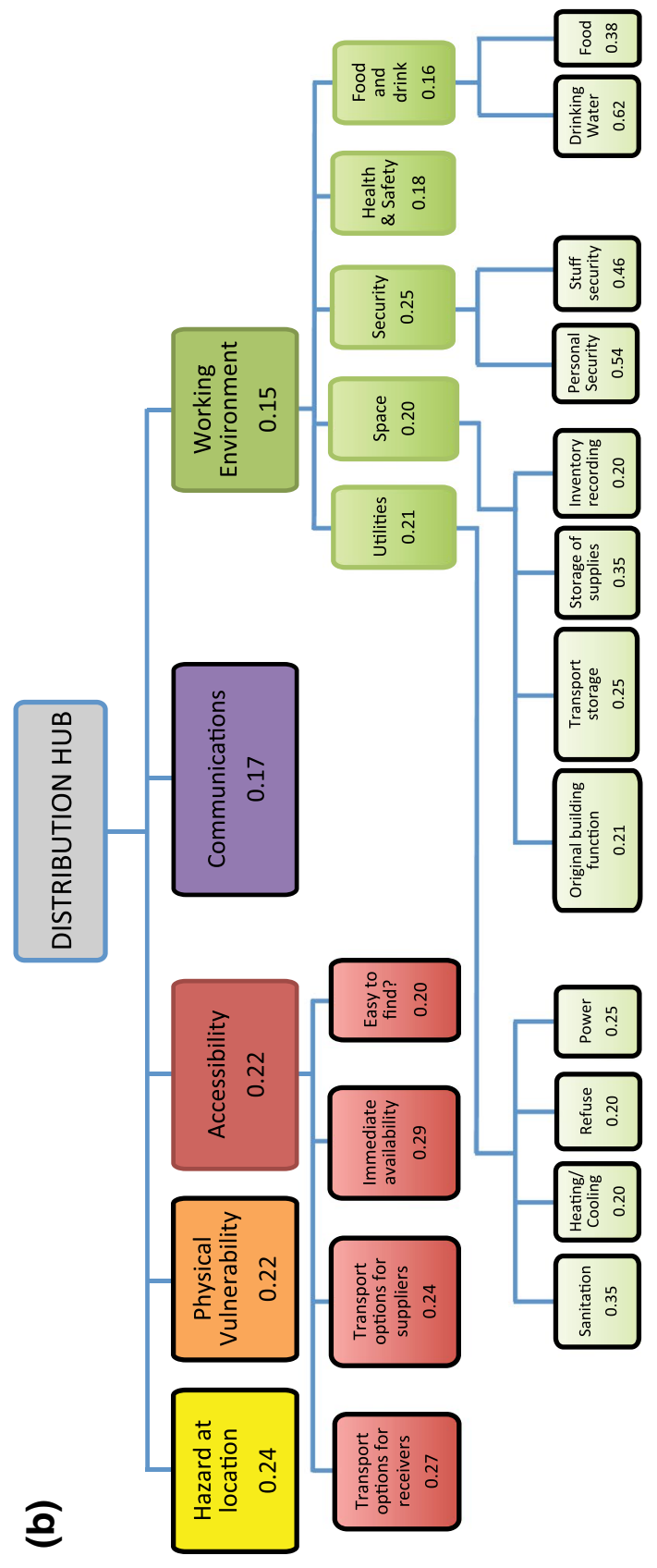

Fig. 3 (continued)

accessibility, communications, living environment and access to supplies for the shelter. The relative importance of these six criteria is compared pairwise with respect to the goal, i.e. the functionality of a school as an evacuation shelter, to obtain the weights for these 
Table 1 Scale of relative importance (Saaty 1980)

\begin{tabular}{ll}
\hline Intensity of importance on an absolute scale & Definition \\
\hline 1 & Equal importance \\
3 & Moderate importance of one over another \\
5 & Essential or strong importance \\
7 & Very strong importance \\
9 & Extreme importance \\
$2,4,6,8$ & Intermediate values between the two adjacent judgments \\
Reciprocals & If $\mathrm{C}_{\mathrm{i}}$ is assigned one of the above numbers when com- \\
& pared with $\mathrm{C}_{\mathrm{j}}$, then $\mathrm{C}_{\mathrm{j}}$ has the reciprocal value when \\
& compared with $\mathrm{C}_{\mathrm{i}}$ \\
\hline
\end{tabular}

criteria. Some of the main criteria are further broken down into subcriteria, and again these are broken down further into subcriteria, ultimately forming the multiple levels of the hierarchy. Weights for all the different subcriteria at each level are obtained by performing pairwise comparisons with respect to the "parent" criterion.

To perform the pairwise comparisons, the scale reported in Table 1 is adopted (Saaty 1980). To formalise these concepts mathematically, let us assume that we have a set of criteria $C_{i}, i=1, \ldots, n$ and the aim is to compute their respective weights $w_{i}, i=1, \ldots, n$. The decision maker has to make a judgement about one pairwise comparison at a time. For example, when comparing criterion $C_{j}$ with $C_{k}$, the relative importance of $C_{j}$ with respect to $C_{k}$ is assessed. This is achieved by expressing a judgement that corresponds to a number, $a_{j k}$, that can be estimated based on Table 1 . The value of $a_{j k}$ is an element of the following vector:

$$
a_{j k}=\{1 / 9,1 / 8,1 / 7,1 / 6,1 / 5,1 / 4,1 / 3,1 / 2,1,2,3,4,5,6,7,8,9\} .
$$

$a_{j k}$ takes a value of 1 when the two criteria are of equal importance, a value greater than 1 when $C_{j}$ is more important than $C_{k}$ and less than 1 when $C_{j}$ is less important than $C_{k}$.

After performing all the pairwise comparisons with respect to the goal (or a specific criterion when subcriteria are compared), the $a_{j k}$ values are collected into a matrix $\mathbf{A}$ which is a square matrix of order $n$. This matrix is symmetric because a condition of multiplicative reciprocity $a_{j k}=1 / a_{k j}, \forall j, k$ holds (Brunelli 2015) therefore the diagonal elements are always 1 (compare each criterion with itself $a_{j j}=1$ ) and only $n(n-1) / 2$ pairwise comparisons need to be performed.

In the ideal case, the comparisons among the criteria are performed in a perfectly consistent manner, $a_{j k}$ is equal to $w_{j} / w_{k}$ exactly and the principal right eigenvalue of $\mathbf{A}$ is exactly equal to its order $n\left(\lambda_{\max }=n\right)$. In the most common case that $a_{j k}$ deviates from the ratio $w_{j} / w_{k}$, the maximum eigenvalue $\lambda_{\max }$ is greater than $n$.

Perfect consistency is achieved in a matrix if

$$
a_{i k=} \frac{w_{i}}{w_{k}}=\left(\frac{w_{i}}{w_{j}}\right) \cdot\left(\frac{w_{j}}{w_{k}}\right)=a_{i j} a_{j k} \forall i, j, k,
$$

where the condition $a_{j k}=w_{j} / w_{k}, \forall j, k$ was applied.

Since the values $a_{j k}$ are assigned by the decision maker without applying any mathematical constraint, it is important to check that the pairwise comparisons yield 
Table 2 Random consistency index $R I_{n}$

\begin{tabular}{lllllllllll}
\hline$n$ & 1 & 2 & 3 & 4 & 5 & 6 & 7 & 8 & 9 & 10 \\
\hline $\mathrm{RI}_{n}$ & 0 & 0 & 0.58 & 0.90 & 1.12 & 1.24 & 1.32 & 1.41 & 1.45 & 1.49 \\
\hline
\end{tabular}

a reasonable lack of inconsistency compared to a limit that is considered acceptable. Saaty proposed the consistency index (Saaty 1977)

$$
C I(A)=\frac{\lambda_{\max }-n}{n-1}
$$

However, this index is not independent of the matrix order and needs to be rescaled. The consistency ratio, $C R$, is the rescaled version of $C I$ :

$$
C R(\boldsymbol{A})=\frac{C I(\boldsymbol{A})}{R I_{n}}
$$

where $C I$ is divided by a real number $R I_{n}$ (random consistency index) that is an estimate of the average $C I$ obtained from a large enough set of randomly generated matrices of size $n$. The random consistency index as a function of $n$ is given in Table 2 (Saaty, 1987). Comparison matrices with values $C R \leq 0.1$ should be considered acceptable. A value of $C R=0.1$ means that the judgements are $10 \%$ as inconsistent as if they had been randomly assigned (Brunelli 2015).

For aggregating opinions from the different participant surveys, we use the aggregation of individual judgements (AIJ) method before the derivation of the priority vector (Forman \& Peniwati, 1998). Matrices $\mathbf{A}_{1}, \ldots, \mathbf{A}_{m}$ are aggregated into a single pairwise comparison matrix $\mathbf{A}_{G}=\left(a_{i j}^{G}\right)_{n x n}$ using the weighted geometric mean (Saaty and Alsina 1986; Aczel and Saaty 1983):

$$
a_{i j}^{G}=\prod_{h=1}^{m} a_{i j}^{(h)^{\frac{1}{m}}}
$$

where $a_{i j}^{(h)}$ is the entry of comparison matrix from the $h$ th decision maker, $m$ is the number of decision makers $(m \geq 2)$, and it is assumed that all decision makers have the same importance (equal weights).

The vector of weights or priority vector is derived from the pairwise comparison matrix $\mathbf{A}_{G}$ using the eigenvector method (Saaty 1980). The priority vector $\mathbf{W}=\left\{w_{i}\right\}$ corresponds to the principal right eigenvector of comparison matrix $\mathbf{A}$. This eigenvector $\mathbf{W}$ corresponds to the eigenvalue $\lambda_{\max }$. The priority vector is subsequently normalised so that the sum of weights is equal to 1 .

\subsection{Questionnaire: gathering pairwise comparisons}

To perform the pairwise comparisons described above, an online survey was distributed to participants (following an initial pilot to check understanding and usability) with expertise and/or experience with evacuation shelters and/or distribution hubs in the Philippines and/or elsewhere. A total of 30 participants contributed from academia (73\%), NGOs (30\%), government (13\%), the private sector (7\%) and international organisations (7\%), with a range of expertise (e.g. disaster management (87\%), engineering (53\%), natural hazards $(53 \%)$, social 
sciences (23\%), physical sciences (23\%), law and governance (13\%), urban planning (10\%)). These included varying levels of experience in evacuation shelters (37\% research, 23\% on-site practitioners, $10 \%$ stayed in a shelter or used the services of a hub, $63 \%$ have experience in the Philippines). The participants were allowed to choose more than one option for the questions related to primary work sector, area of expertise and experience.

Participants were asked to compare the relative importance of each criterion within a level group (i.e. those coming off a single branch in Fig. 3) using the scale in Table 1. Explanations of each criteria were provided during selection (see Table 3). The results were then amalgamated in order to calculate the criteria weightings. Sensitivity tests were carried out by comparing weightings derived from all participants with those from selected sectors and backgrounds to determine whether particular experience and background affected perceptions of importance.

The comparison matrices for each participant were checked for inconsistencies calculating the consistency ratio $(C R)$ metric for each matrix. In the case that inconsistencies $(C R>0.1)$ were observed, as was the case for two comparison matrices in this study that had $C R$ values up to 0.2 , the decision maker should revise their judgments to eliminate them and come up with values of $C R \leq 0.1$. In this specific exercise that was thought not practical to do as the comparisons were performed as part of an anonymous survey. Applying aggregation of individual judgments (AIJ) though yielded comparison matrices that were not inconsistent for all cases and this method was adopted to get the aggregated priority vector $\mathbf{W}^{G}$ for each comparison considered. Note that we checked what the effect of removing the comparison matrices with $C R>0.1$ on the final weights would be and confirmed that the final weights would not be altered.

\subsection{Surveying schools to assign scores for each building}

For each criterion at each school building, an integer score between 1 and 5 ( 1 being the best and 5 the lowest) was assigned. When determining the score of the individual components, the criteria were checked by working down from 1 to 5 for each category to see which score should be given. Note that to score a higher score, all the conditions for that score must be met. Table 4 shows an overview of the scoring system developed for the local context of Cagayan de Oro. The detailed scoring system used in the field surveys, providing what is required for a score of $1,2,3,4,5$ for each criterion, is included in the Appendix along with details about the score design for some of the criteria. This can be applied to other areas within the Philippines and could be adapted for local contexts elsewhere in consultation with local expertise.

The criteria scores were determined through in situ surveys and onsite interviews with school representatives in November 2018 to ascertain information not obtainable through inspection alone (official permission from the Philippines Department of Education was secured prior to conducting school surveys), augmented by desktop study.

The physical vulnerability scores were defined adopting the rapid yet reliable visual multi-hazard vulnerability prioritisation method (Nassirpour et al. 2017). The method uses a one-page data collection form that is completed by the surveyor based on visual inspection of the exterior and if possible, the interior of a building. It does not require access to detailed structural drawings or design reports. The form is designed to allow the user to document information on the building's geolocation and main structural characteristics and deficiencies that are used to assess the structural integrity and ability of the building to withstand lateral and vertical loading from the seismic ground shaking, flood and wind 
Table 3 Explanation of criteria shown in Fig. 3

Hazard at location

Physical vulnerability

Accessibility (SHELTER)

Communications

Living environment

Access to supplies

Proximity to affected

Transport options

Easy to find

Utilities (SHELTER)

Space (SHELTER)

Security

Health and Safety

Water

Food

Medical

Bedding

Sanitation

Washing

Heating/Cooling

Refuse

Power

Original building function

Space for people

Space for administration

Personal security (SHELTER)

Stuff security (SHELTER)

Space for sleeping

Space for eating

Recreation
Refers to the hazard of, e.g. flooding, earthquake, etc. at the site of the building

Is how well the building performs in response to the hazard, i.e. how well does the building maintains its structural integrity

Includes the proximity to those affected, transport options and whether the building is easy to find

Include phone, internet, radio, etc.

Includes the utilities, space, security and health and safety

Refers to the access, storage and distribution of supplies including water, food, medical supplies and bedding

Refers to the proximity of the shelter to those who need to use it

Refers to how easy it is to access via foot, private and public transport including routes and parking

Refers to whether the building is easy to find, i.e. its visibility and whether there is necessary signage

Include sanitation (i.e. access to clean water and sewage disposal), washing, power, heating/cooling and refuse (solid waste)

Refers to available space in the building for people, administration and to maintain the original building function

Refers to personal security and security of public and private possessions

Refers to evacuation routes, fire protection and access to medical assistance

Refers to access to clean drinking water on-site and availability of back up water source

Refers to access to food on-site and availability of fridge and heating facilities

Refers to access to medical supplies on-site and availability of appropriate storing facilities

Refers to availability of bedding to be used by the shelter residents

Refers to the provision of clean water and adequate sewage disposal, note provided facilities should take into account vulnerable groups such those with disabilities or the elderly

Refers to having appropriate facilities for showering/bathing and face washing taking into account vulnerable groups such as those with disabilities or the elderly

Refers to availability of ventilation and heating/cooling systems on-site

Refers to solid waste disposal, i.e. the removal of rubbish/garbage/trash

Refers to availability of power and backup power facilities

Refers to keeping the school functioning while being used as a shelter/distribution hub, i.e. classes continue

Refers to space for sleeping, eating and recreation

Refers to space for administration such as registration, an information point and provision of medical services

Refers to the security of residents and staff working in the shelter

Refers to the security of supplies, school property and personal belongings of the residents and staff working in the shelter

Includes the total amount of space available and the ability to have separate spaces

Refers to the availability of dedicated dining room and cleaning facilities

Refers to privacy, prayer, quiet room and social space 
Table 3 (continued)

\begin{tabular}{|c|c|}
\hline Medical services & $\begin{array}{l}\text { Refers to private space used to provide medical services to residents on- } \\
\text { site }\end{array}$ \\
\hline Storage of supplies & Refers to availability of space and means to store and preserve supplies \\
\hline Registration & Refers to space used to check in and out shelter residents \\
\hline Size & Refers to total amount of space available \\
\hline Multiple spaces & $\begin{array}{l}\text { Refers to the ability to have separate spaces available for families, gender- } \\
\text { specific spaces and those who feel vulnerable }\end{array}$ \\
\hline Accessibility (HUB) & $\begin{array}{l}\text { Includes transport options for suppliers and receivers, immediate avail- } \\
\text { ability and whether the building is easy to find }\end{array}$ \\
\hline Working environment & $\begin{array}{l}\text { Includes the utilities, space, security, health and safety and food and drink } \\
\text { options }\end{array}$ \\
\hline Transport options for receivers & $\begin{array}{l}\text { Refers to convenience of foot, public and private transport for people arriv- } \\
\text { ing to the hub to receive supplies and distribute them to those in need }\end{array}$ \\
\hline Transport options for suppliers & $\begin{array}{l}\text { Refers to convenience of foot, public and private transport for those sup- } \\
\text { plying the resources either directly or from a collection point }\end{array}$ \\
\hline Immediate availability & $\begin{array}{l}\text { Refers to whether the building is available to be used as a distribution hub } \\
\text { right after the event, as opposed to needing time to set it up }\end{array}$ \\
\hline Utilities (HUB) & Include sanitation, power, heating/cooling and refuse \\
\hline Space (HUB) & $\begin{array}{l}\text { Refers to available space in the building for transport and supplies storage, } \\
\text { inventory recording and to maintain the original building function }\end{array}$ \\
\hline Food and drink & $\begin{array}{l}\text { Refers to on-site or nearby access to clean drinking water and food for the } \\
\text { staff working in the distribution hub }\end{array}$ \\
\hline Transport storage & $\begin{array}{l}\text { Refers to space for keeping vehicles securely, parking vehicles and space } \\
\text { for loading and unloading }\end{array}$ \\
\hline Inventory recording & Refers to space availability and accessibility from and to storage place \\
\hline Personal security (HUB) & Refers to security of staff working in the distribution hub \\
\hline Stuff security (HUB) & $\begin{array}{l}\text { Refers to inventory, school property and personal belongings of the staff } \\
\text { working in the distribution hub }\end{array}$ \\
\hline Drinking water & $\begin{array}{l}\text { Refers to access to clean drinking water on-site and availability of back up } \\
\text { water source }\end{array}$ \\
\hline
\end{tabular}

pressure. Examples of information on the main structural characteristics include a building's lateral load resisting system and materials, year of construction, number and dimensions of columns and beams, foundation type, number and dimensions of openings. Some of these parameters are relevant for all perils, e.g. the age and materials of the buildings, while others are peril specific, e.g. the percentage of openings in a building correlated with its flood vulnerability. Once data are collected the factors with the highest contribution to physical vulnerability for each peril are identified. For each contributing factor, a set of relevant attributes are defined that are assigned a vulnerability rating on a scale from 0 to 100 , with 0 corresponding to lowest and 100 to highest vulnerability. Finally, the vulnerability ratings for each of the identified factors are combined to return an overall physical vulnerability score for each surveyed building and for each peril, i.e. earthquake, flood and wind. The score for physical vulnerability is the average of the score for the individual perils. A total of 38 school buildings were visually surveyed in Cagayan de Oro using the visual multi-hazard vulnerability prioritisation method (Nassirpour et al. 2017); 28 school buildings were surveyed in 2016 as part of a previous project (SCOSSO, 2016) and 10 during the November 2018 site visits. 
Table 4 Summary of scoring system used to determine the scores for the different criteria. See Appendix for a detailed scoring system used in the field surveys

\begin{tabular}{|c|c|}
\hline Criteria & Factors considered for each criteria score \\
\hline Flood hazard & Scores developed based on the flood depth at different return periods \\
\hline Earthquake hazard & $\begin{array}{l}\text { Scores developed based on the Modified Mercalli Intensity level with } \\
20 \% \text { probability of exceedance in } 50 \text { years was considered }\end{array}$ \\
\hline Wind hazard & $\begin{array}{l}\text { Scores developed based on the maximum sustained wind speed for } 300 \text { - } \\
\text { year return period }\end{array}$ \\
\hline Flood vulnerability & $\begin{array}{l}\text { Scores were assigned using the visual multi-hazard vulnerability prioriti- } \\
\text { sation method }\end{array}$ \\
\hline Seismic vulnerability & $\begin{array}{l}\text { Scores were assigned using the visual multi-hazard vulnerability prioriti- } \\
\text { sation method }\end{array}$ \\
\hline Wind vulnerability & $\begin{array}{l}\text { Scores were assigned using the visual multi-hazard vulnerability prioriti- } \\
\text { sation method }\end{array}$ \\
\hline Transport options & $\begin{array}{l}\text { Foot, public and private transport options were considered. We consid- } \\
\text { ered quality of footpaths, roads and availability and frequency of public } \\
\text { transport and combined the scores from these. A score of } 1 \text { required } \\
\text { access for those with disabilities }\end{array}$ \\
\hline Proximity to affected & $\begin{array}{l}\text { The average distance of the school complex to the barangay boundaries } \\
\text { was considered }\end{array}$ \\
\hline Easy to find & $\begin{array}{l}\text { We considered whether the school complex location is known to the com- } \\
\text { munity, signage availability for motorists and pedestrians to the school } \\
\text { complex entrance and designated shelter rooms, ability to use Google } \\
\text { Maps (or equivalent mobile app) to navigate to the correct school } \\
\text { entrance }\end{array}$ \\
\hline Communications & $\begin{array}{l}\text { We considered radio, TV, reliable phone line and reliable fast internet } \\
\text { availability. A score of } 1 \text { required backup power }\end{array}$ \\
\hline Sanitation & $\begin{array}{l}\text { The number of persons per basin and toilet in the shelter was considered. } \\
\text { A score of } 1 \text { required access for those with disabilities }\end{array}$ \\
\hline Washing & $\begin{array}{l}\text { The number of persons per showering facility in the shelter was consid- } \\
\text { ered. A score of } 1 \text { required access for those with disabilities }\end{array}$ \\
\hline Heating/Cooling & $\begin{array}{l}\text { Availability of properly functioning and reliable cooling system (i.e. air } \\
\text { conditioning) was considered. If that was not available, we considered } \\
\text { building ventilation metrics such as fans and percentage of openings }\end{array}$ \\
\hline Refuse & $\begin{array}{l}\text { Availability and capacity of solid waste collection (rubbish bins), avail- } \\
\text { ability and frequency of removal service (truck to collect rubbish) were } \\
\text { considered }\end{array}$ \\
\hline Power & $\begin{array}{l}\text { Availability and reliability of power and backup power facilities was } \\
\text { considered }\end{array}$ \\
\hline Original building function & $\begin{array}{l}\text { We considered whether the school has extra rooms and spaces and the } \\
\text { percentage of students who continue classes normally. A score of } 1 \\
\text { required separate extra rooms and spaces from the shelter rooms }\end{array}$ \\
\hline Personal security & $\begin{array}{l}\text { We considered security of residents and staff working in the shelter and if } \\
\text { there have been any past incidents, the measures taken to prevent future } \\
\text { issues. A score of } 1 \text { required security ensured for vulnerable groups, i.e. } \\
\text { women, children, elderly }\end{array}$ \\
\hline Stuff security & $\begin{array}{l}\text { We considered security of supplies, school property and personal belong- } \\
\text { ings of the residents and staff working in the shelter and if there have } \\
\text { been any past incidents, the measures taken to prevent future issues. A } \\
\text { score of } 1 \text { required security ensured for vulnerable groups, i.e. women, } \\
\text { children, elderly }\end{array}$ \\
\hline
\end{tabular}


Table 4 (continued)

\begin{tabular}{|c|c|}
\hline Criteria & Factors considered for each criteria score \\
\hline Health and safety & $\begin{array}{l}\text { Availability of proper evacuation routes (double-swing or swing-out } \\
\text { doors), fire protection system and access to medical assistance were } \\
\text { considered. A score of } 1 \text { required accessibility for all (i.e. ramps avail- } \\
\text { able for evacuation of elderly and wheelchair users) }\end{array}$ \\
\hline Water & $\begin{array}{l}\text { Onsite access to clean drinking water onsite and availability of back up } \\
\text { water source from onsite sources were considered. We also considered } \\
\text { whether there is a pre-existing formal arrangement in place for extra } \\
\text { water to be delivered in the event of an emergency }\end{array}$ \\
\hline Food & $\begin{array}{l}\text { Access to non-contaminated food and availability of sufficient fridge/ } \\
\text { freezer and heating facilities onsite were considered. We also consid- } \\
\text { ered whether there is a pre-existing formal arrangement in place for it to } \\
\text { be delivered in the event of an emergency }\end{array}$ \\
\hline Medical supplies & $\begin{array}{l}\text { Access to medical supplies, availability of advanced first aid and proper } \\
\text { storing facilities onsite were considered. We also considered whether } \\
\text { there is a formal pre-existing arrangement in place for stocks to be } \\
\text { replenished when required if there is an emergency }\end{array}$ \\
\hline Bedding & $\begin{array}{l}\text { We considered clean bedding availability either onsite or through a pre- } \\
\text { existing arrangement }\end{array}$ \\
\hline Size & The area of sleeping space per person was considered \\
\hline Multiple spaces & $\begin{array}{l}\text { We considered the max number of families or people that can be accom- } \\
\text { modated per room }\end{array}$ \\
\hline Space for eating & $\begin{array}{l}\text { Availability of dedicated dining room and cleaning facilities (proper dish } \\
\text { washing, cleaning tables) on-site were considered }\end{array}$ \\
\hline Recreation & $\begin{array}{l}\text { We considered the number of separate appropriate rooms for privacy, } \\
\text { prayer, quiet room and social spaces available }\end{array}$ \\
\hline Medical services & $\begin{array}{l}\text { We considered the number of rooms dedicated to provide medical ser- } \\
\text { vices with hygienic conditions and its availability }\end{array}$ \\
\hline Storage of supplies & $\begin{array}{l}\text { Availability of storing space with proper moisture and temperature condi- } \\
\text { tions, fridges and freezers were considered }\end{array}$ \\
\hline Registration & $\begin{array}{l}\text { We considered the availability of a dedicated registration space and its } \\
\text { location in the building }\end{array}$ \\
\hline Immediate availability & $\begin{array}{l}\text { We considered the need for restoration of the building following a disas- } \\
\text { ter and the amount of time required to be completed }\end{array}$ \\
\hline Transport storage & $\begin{array}{l}\text { We considered sufficiency of space for keeping vehicles securely, space } \\
\text { for parking vehicles and space for loading and unloading }\end{array}$ \\
\hline Inventory recording for supplies & $\begin{array}{l}\text { We considered availability of dedicated inventory recording space, its } \\
\text { signage and its accessibility from drop-off location and to storage place. } \\
\text { A score of } 1 \text { required proper moisture and temperature conditions }\end{array}$ \\
\hline
\end{tabular}

\subsection{Combining weights and scores-obtaining relative suitability for the different school buildings}

The weightings for each criterion were multiplied by the criteria scores for each school building to calculate the relative suitability of the building. This provides the relative suitability scores for the different possible buildings to inform which may be more or less appropriate to use and to highlight where improvements need to be made overall or at the individual building level. 


\section{Results}

\subsection{Priority vector}

Figure 3 shows the relative weightings for the different categories within each layer for schools being used as (a) evacuation shelters and (b) distribution hubs, as determined through the survey and AHP. The final weights for the measured criteria (those at the lowest levels) are shown in Fig. 4; note that these sum to one.

Hazard at location and physical vulnerability are considered the most important toplevel criteria (each accounting for approximately a quarter of the weighting) for both evacuation shelters and aid distribution hubs, with accessibility considered as important as physical vulnerability in the case of aid distribution hubs. For evacuation shelters, while hazard at location and physical vulnerability account for half the weighting score, the other half of the weighting is almost equally distributed among the rest of the criteria: accessibility, communications, living environment and access to supplies indicating that the quality of the experience equally depends on all these factors.

Considering lower levels in the hierarchy, the survey participants have assigned similar relative weights among many factors for shelters and hubs. For shelters, high weights have been given to sanitation and access to water, personal security, space for sleeping, health and safety and medical services. In addition to these factors, high weights were assigned to original building function and multiple spaces.

\subsection{Analysis of results for different questionnaire respondent subgroups}

The sector, background and experience of survey respondents do not appear to significantly affect the order and values of the weights for the different criteria indicating that no significant biases exist within subgroups with specific expertise and experience. The detailed results showing the final priorities or weights obtained for each factor for different subgroups for the shelter and hub are provided in Online Resource 1. In most cases, where variation in the criteria priority order does occur across different subgroups, this is likely due to the closeness of the weights, i.e. a small change of the weights would reorder the criteria. For example, when considering the rankings for the top-level criteria for shelters (hazard at location, physical vulnerability, accessibility, communications, living environment and access to supplies), all groups selected vulnerability and hazard as the most important except for non-academia and NGO subgroups, with the latter ranking accessibility higher in priority than hazard and rating access to supplies as more important than the living environment. The weights for the hubs by the different subgroups reveal higher variability in the order of the top-level criteria than for shelters, but again most differences in actual weightings are small between different subgroups.

A difference between subgroups is noted for the relative importance of having the "original building use" returned, with a higher importance for this noted among those with direct experience working or staying in a shelter and those with direct experience within the Philippines. Another significant difference between subgroups' assessment of the relative importance of factors is that while most subgroups assigned the lowest weight to heating/cooling under the utilities criterion, the subgroup that has practical experience with shelters believes that this has a higher priority than refuse management and equal priority to power. 


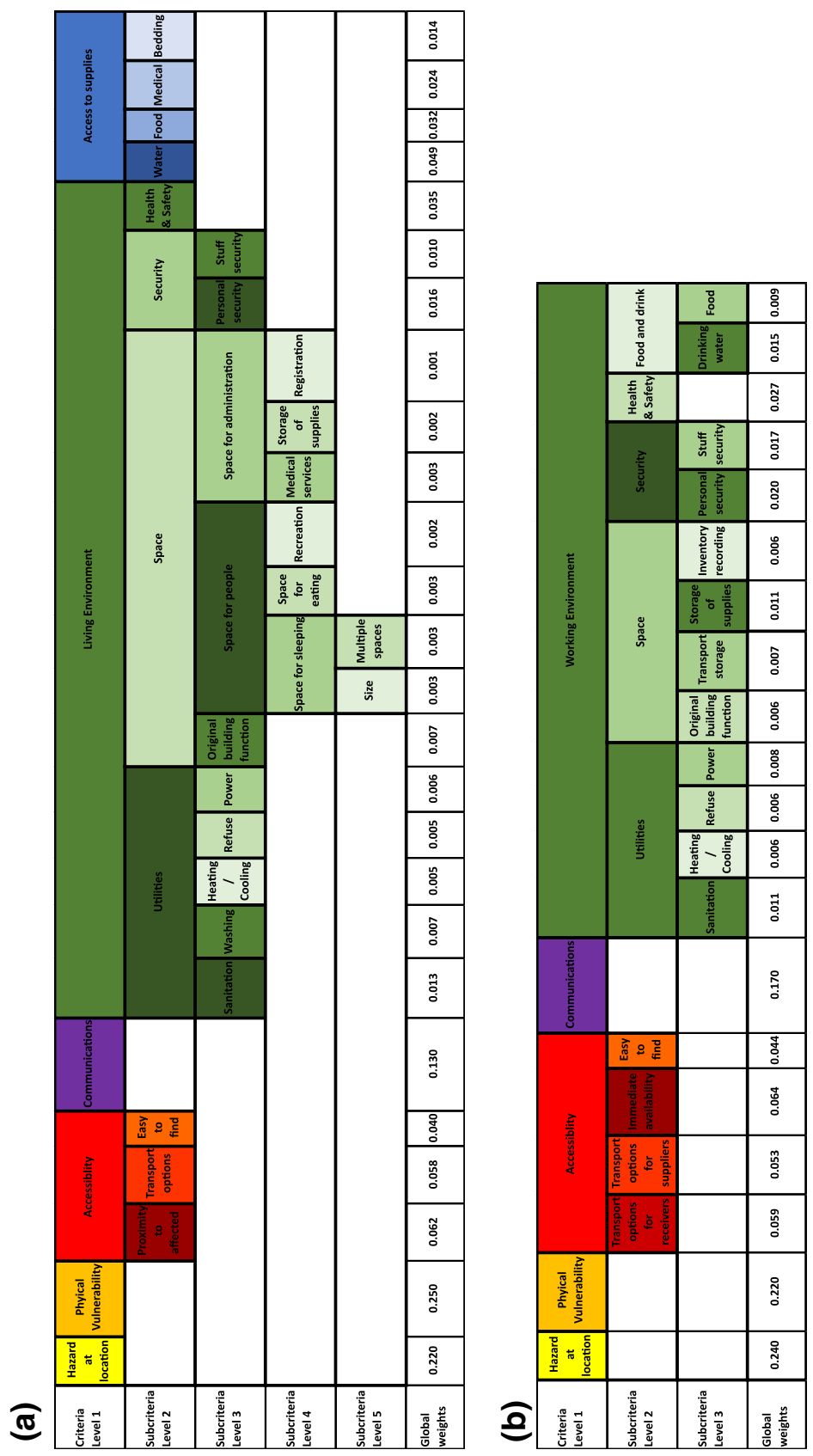

$\stackrel{0}{\Xi}$

.

宅

륧

60

ప̄

क

80

ฮ

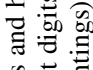

s.

论

$\vec{\Xi}$

$\exists 0$

空至

을

焉离

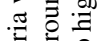

$\stackrel{\square}{0}$

0 .

ज के

Q

당ㅇㅇ

$8 \%$

ㅇ

然

:

乙ँ ऐ

일

है

옳

혀

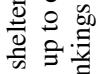

저ㅎㅠㅠ 혼

후류

굴

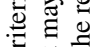

苛吾

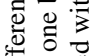

$\stackrel{0}{0}$

Ð

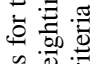

on

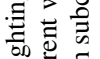

跑

चี

江

+ 岁江

운 


\subsection{Suitability scores for school buildings surveyed}

Table 5 summarises the number of schools assigned each score range and the number of schools having shelter and hub suitability indices within the defined ranges. The final shelter and hub suitability indices have been estimated for each individual peril based on the respective hazard and physical vulnerability scores, e.g. the flood suitability index for shelter and hubs are calculated using the flood hazard and flood vulnerability scores. The combined hazard is the average of the score for individual perils, similar to combined physical vulnerability. The combined suitability index is evaluated using the combined hazard and physical vulnerability scores along with the rest of the criteria.

Structurally, a number of the surveyed buildings were judged as requiring moderate to major restoration (i.e. more than 4 days of work) to provide suitable and safe shelter. In such cases, it is recommended where possible that these schools are not used as primary emergency evacuation shelters unless prior modification is possible.

In terms of access and transport, many schools had good private and public transport access options; however, they lacked adequate accessibility when on foot, which brought down their overall score. Uneven ground made a number of schools less safe for night evacuations and difficult for those with disabilities or problems with walking. Almost half of the surveyed buildings were classified as "Unpaved, difficult to walk on footpath with obstacles (moderate difficulty) (e.g. uneven ground, need to cross major roads)" or worse.

Given that there are a high number of shelters within the town, most school buildings scored well on being close to those potentially affected. However, this can also mean that the school buildings are exposed to the same hazards and therefore the buildings need to be built with low structural vulnerability.

The personal security and security of possessions were found to be relatively poor at a number of surveyed schools, which may disincentivise those communities from using those schools as shelters in crisis situations.

Space and function limitations were highlighted through school buildings not being able to support separate spaces for different activities such as eating and having inadequate cleaning facilities.

Interviews with SDRRM (School Disaster Risk Reduction Management) coordinators conducted during school surveys revealed that when evacuees leave school buildings to alternative shelters or to return home, school facilities are left damaged and with no dedicated budget for repairs. Moreover, although solid waste management protocols are in place in schools, extensive cleaning is still necessary in order to return to a normal state, and students and teachers are relied upon to undertake this before education can resume. This both increases the burden on education staff and delays the resumption of teaching.

As many schools remain under-prepared for supporting the social needs of populations, the Department of Education (DepEd) in the Philippines advocates not using schools as emergency shelters except in extreme circumstances when areas have no other structurally safe building capable of surviving a major hazard. Although three of the surveyed schools surveyed in this study proved unsuitable, having "no extra rooms and spaces" so that "students cannot continue at all while the shelter is being used", many others had the capacity to continue education as normal either completely, or for $75 \%$ of students, due to extra space available for sheltering populations. For those schools yet unable to accommodate classes while housing evacuees, DepEd has implemented "emergency classes" in which students are temporarily moved to classrooms not being used as shelters and shared, with two classes in each room being conducted in shifts so that the customary eight hours 
Table 5 Number of school buildings with assigned score ranges for each criterion. This table shows which criteria scored well, which scored poorly and where there were narrow and wide distributions. Note that [a, b] denotes the set of scores between $\mathrm{a}$ and $\mathrm{b}$ inclusive, whereas $(\mathrm{a}, \mathrm{b}]$ denotes the set of scores between $\mathrm{a}$ and $\mathrm{b}$ with $\mathrm{b}$ but not a included in the set. Colours vary from red to yellow to differentiate high from low values with the largest value in bold font

\begin{tabular}{|c|c|c|c|c|c|}
\hline \multirow{2}{*}{ Criteria } & \multicolumn{5}{|c|}{ Score range } \\
\hline & {$[0,1]$} & $(1,2]$ & $(2,3]$ & $(3,4]$ & $(4,5]$ \\
\hline Flood hazard & 22 & 9 & 4 & 3 & 0 \\
\hline Earthquake hazard & 0 & 0 & 0 & 38 & 0 \\
\hline Wind hazard & 0 & 0 & 0 & 0 & 38 \\
\hline Combined hazard & 0 & 0 & 22 & 16 & 0 \\
\hline Flood vulnerability & 0 & 20 & 18 & 0 & 0 \\
\hline Seismic vulnerability & 0 & 10 & 13 & 15 & 0 \\
\hline Wind vulnerability & 0 & 9 & 20 & 9 & 0 \\
\hline $\begin{array}{l}\text { Combined physical } \\
\text { vulnerability }\end{array}$ & 0 & 11 & 22 & 5 & 0 \\
\hline Transport options & 0 & 12 & 7 & 15 & 4 \\
\hline Proximity to affected & 9 & 14 & 9 & 6 & 0 \\
\hline Easy to find & 2 & 0 & 30 & 6 & 0 \\
\hline Communications & 1 & 0 & 18 & 16 & 3 \\
\hline Sanitation & 1 & 3 & 13 & 14 & 7 \\
\hline Washing & 0 & 3 & 14 & 14 & 7 \\
\hline Heating/Cooling & 0 & 0 & 38 & 0 & 0 \\
\hline Refuse & 0 & 1 & 34 & 0 & 3 \\
\hline Power & 3 & 32 & 0 & 3 & 0 \\
\hline Original building function & 5 & 10 & 1 & 0 & 22 \\
\hline Personal security & 0 & 8 & 28 & 2 & 0 \\
\hline Stuff security & 0 & 11 & 10 & 6 & 11 \\
\hline Health \& Safety & 0 & 23 & 12 & 3 & 0 \\
\hline Water & 0 & 1 & 23 & 10 & 4 \\
\hline Food & 0 & 0 & 11 & 3 & 24 \\
\hline Medical supplies & 0 & 5 & 19 & 13 & 1 \\
\hline Bedding & 0 & 0 & 1 & 0 & 37 \\
\hline Size & 0 & 5 & 17 & 5 & 11 \\
\hline
\end{tabular}


Table 5 (continued)

\begin{tabular}{|c|c|c|c|c|c|}
\hline Multiple spaces & 11 & 9 & 7 & 4 & 7 \\
\hline Space for eating & 0 & 1 & 0 & 9 & 28 \\
\hline Recreation & 0 & 5 & 0 & 18 & 15 \\
\hline Medical services & 0 & 5 & 24 & 1 & 8 \\
\hline Storage of supplies & 0 & 0 & 5 & 13 & 20 \\
\hline Registration & 3 & 15 & 2 & 0 & 18 \\
\hline Immediate availability & 0 & 2 & 0 & 0 & 36 \\
\hline Transport storage & 9 & 9 & 15 & 2 & 3 \\
\hline $\begin{array}{l}\text { Inventory recording for } \\
\text { supplies }\end{array}$ & 0 & 0 & 0 & 0 & 38 \\
\hline $\begin{array}{l}\text { Shelter flood suitability } \\
\text { index }\end{array}$ & 0 & 1 & 30 & 7 & 0 \\
\hline $\begin{array}{l}\text { Shelter earthquake } \\
\text { suitability index }\end{array}$ & 0 & 0 & 12 & 26 & 0 \\
\hline $\begin{array}{l}\text { Shelter wind suitability } \\
\text { index }\end{array}$ & 0 & 0 & 1 & 35 & 2 \\
\hline Hub flood suitability index & 0 & 0 & 25 & 13 & 0 \\
\hline $\begin{array}{l}\text { Hub earthquake suitability } \\
\text { index }\end{array}$ & 0 & 0 & 6 & 32 & 0 \\
\hline Hub wind suitability index & 0 & 0 & 1 & 34 & 3 \\
\hline $\begin{array}{l}\text { SHELTER COMBINED } \\
\text { SUITABILITY INDEX }\end{array}$ & 0 & 0 & 15 & 23 & 0 \\
\hline $\begin{array}{l}\text { HUB COMBINED } \\
\text { SUITABILITY INDEX }\end{array}$ & 0 & 0 & 12 & 26 & 0 \\
\hline
\end{tabular}

of education are still achieved. The eventual aim is to transition to a new school building design where a roof-level layer is used as evacuation space, but until then conducting classes in shifts where possible remains prevalent.

\section{Discussion}

Saving lives goes beyond preventing fatalities. Preventing mortality is a primary concern for shelter provision so evacuation shelters need to provide protection against life-threatening conditions. However, beyond that basic function, the quality of experience once at the shelter will influence those facing hazard-related dangers to evacuate and display safetyseeking behaviour more consistently, likely saving further lives as well as affecting the ability of those affected to recover following an event. The suitability of a building as an emergency shelter and aid distribution hub should consider both the physical attributes and the conditions for those living and working there, as indicated by the relative weightings 
assigned for the top-level criteria in our study and in agreement with temporary shelter guidelines (e.g. FEMA, The Sphere Project, UK Government). Physical well-being and satisfying basic human needs at the shelter is a priority, indicated by the relatively high priorities given to sanitation and access to water, personal security, space for sleeping, health and safety and medical services. In addition, high priority is also given to the ability to maintain the normal state of being and not disrupt education in the survey results, having been highlighted by several international organisations and recognised shelter standards. Furthermore, a shelter's capability to provide multiple spaces for families or small groups of evacuees living in a more private environment was evaluated as being more important than the capacity of the shelter itself. For aid distribution hubs on the other hand, the higher weighting given to accessibility relative to communications and working environment likely arises from the assumption that the ability to transport supplies easily to the distribution point and access the supplies from a receiver perspective in the immediate aftermath of a hazard event is crucial for effective hub function. A further differentiating point for hubs compared to shelters is the selection of security followed by utilities and space as the top choice under the working environment factor. The hubs only serve as working and not living spaces and the quality of their utilities and space is of secondary importance.

Descriptive guidelines alone do not allow a systematic approach to comparing the relative suitability of emergency shelter and aid distribution hub options; we provide a quantitative and objective approach to comparing the relative importance of different criteria, including both objective and subjective features. Existing guidelines for shelters both internationally and in the Philippines are primarily descriptive and therefore subject to interpretation. It is important that they are reassessed to include quantitative measures and additional considerations highlighted through the weights calculated in this study. Maintaining the original building function is ranked high in the shelter priorities and should be both explicitly referenced and accounted for in international guidelines and practices for shelter selection and use. Other factors with high importance that are not sufficiently considered in the international guidelines include the use of multiple spaces to provide a sense of privacy and security, especially for families and the most vulnerable shelter residents. Security of self and possessions is also not adequately referenced in the guidelines but could have negative impacts such as crime, violence, a sense of neglect and fear, and damage to buildings which may cause local populations to feel unsafe and choose not to evacuate. The relative scoring methodology proposed in this study can be applied in different geographical contexts for multiple purposes by adapting the factors and scoring system for the main criteria.

A relative suitability scoring system derived from weighted criteria and assessed scores for each building aids optimal decision-making. First, stakeholders could use the relative scores to decide rapidly and a priori the most suitable buildings to assign as shelters predisaster. Second, the scoring framework may be used after a hazard event to allow decision makers to select which school buildings should function as shelters and aid distribution hubs in the region. Buildings that suffer significant damage, are situated in high hazard areas (e.g. schools in a potential landslide zone that may be triggered by aftershocks) or are not accessible (e.g. due to road closures) should be excluded from consideration. Third, scores may indicate areas to prioritise for improvement and where interventions and retrofitting could have highest benefits (significant increases of low scores but without overfitting measures precisely to the scoring system), especially with limited resources and budgets. Ultimately, if the scoring system is applied to different towns and regions in the Philippines or other countries, joint learning may be achieved through lessons learned and feedback being shared. 
Some immediately identifiable challenges among the schools in Cagayan de Oro become evident from examining the scores of the individual buildings surveyed. These challenges, although serious enough to prevent people from seeking and staying in evacuation shelters, could be relatively easy to address, without the need to make large scale changes at significant expense. For example, for ease of finding a designated shelter or hub, scores were generally low (3 or 4). A quick and inexpensive improvement would be installing signage to the entrance to a school complex, to designated shelter and hub rooms, and signage for motorists and pedestrians in the town. Communication scores were generally low, so to improve, radios, TV, a reliable phone line and fast internet with backup power could be installed for a relatively small investment. New technologies are becoming increasingly more affordable and can bring great benefit. Furthermore, schools scored very low on allowing the building to return to its original function; this requires immediate measures for improvement.

Minimising the disruption to education caused by using schools as evacuation shelters is an essential consideration for holistic recovery, preventing long-term education deficiencies emerging and increasingly negative impacts in disaster locations. Within our survey, those with direct experience in the Philippines or practical experience with shelters and hubs placed a higher importance on the original building function being able to continue than those without such experience, likely because the former have seen the negative impacts on the quality of education and academic progress. The advice highlighted through this study is to concentrate on alternative shelter options in the vicinity of the schools so that education can be resumed as quickly as possible following a crisis. Where this is not possible however, we suggest assessing plans to move evacuees to shelters better able to accommodate displaced persons while restarting educational activities as soon as feasible following an event. We note that other community buildings can also interfere with community functions, so even if alternate buildings to schools are used, the possibility to use the building for its original function likely needs to be considered.

Multi-hazard risk assessment and management has gained increasing interest among the contemporary international disaster management community. The Sendai Framework for Disaster Risk Reduction 2015-2030 calls for increased access to Multi-Hazard Early Warning Systems and multi-hazard disaster risk information and assessments by 2030 (United Nations, 2015). However, determining shelters under multi-hazard criteria with a "one size fits all" approach may result in the suboptimal selection of buildings as shelters for some hazards. The selection of a different set of optimal buildings for different hazards, multi-hazard events and cascading events, however, may create additional confusion in the community with too many different instructions depending on the exact nature of the event preventing an efficient and effective evacuation of the population. Therefore, our method for calculating relative suitability for shelters and hubs based on individual hazards separately and multi-hazards together is desirable as it allows decision makers to use informed decisions regarding the relative benefits of individual hazard suitability optimisation versus providing simple instructions in the light of multiple possible perils.

\section{Conclusions}

Expert opinions were amalgamated using the analytical hierarchy process to create relative weights of criteria for consideration in determining the relative suitability of different school buildings for use as evacuation shelters and distribution hubs. A scoring system for 
the criteria was applied to individual school buildings in the case study city of Cagayan De Oro, Philippines, which can be adapted for other regions and types of building usage. Once combined, this can be used to inform the optimal selection of school buildings to be used as shelters and hubs before and after a disaster, prioritise the retrofitting of buildings, identify areas of improvement and adopt a multi-hazard emergency shelter strategy.

A relatively equal importance assigned between the physical safety of the building (the hazard at the location and the physical vulnerability) and social-based criteria which affect the experience of those using the shelter (accessibility, communications, living or working environment and access to supplies) demonstrates the broad requirements for ensuring shelters are safe, dignified and a viable evacuation option. Although there were some minor differences in the weights computed from different subgroups, overall we do not find that participants' expertise and background significantly changed their views of the relative importance of different factors.

In the light of the assessment of 38 school buildings in Cagayan de Oro, the Philippines, we recommend the installation of additional means of communications and signage for finding and accessing shelter buildings to improve the overall suitability scores of the surveyed buildings. We further recommend the use of alternative shelter options next to the schools so that education is not disrupted when there is not capacity to accommodate evacuees while resuming education in the same building.

Acknowledgements The research was funded through the PRISMH project, awarded through the British Council. We thank two anonymous reviewers for recommendations that helped improve the manuscript.

Open Access This article is licensed under a Creative Commons Attribution 4.0 International License, which permits use, sharing, adaptation, distribution and reproduction in any medium or format, as long as you give appropriate credit to the original author(s) and the source, provide a link to the Creative Commons licence, and indicate if changes were made. The images or other third party material in this article are included in the article's Creative Commons licence, unless indicated otherwise in a credit line to the material. If material is not included in the article's Creative Commons licence and your intended use is not permitted by statutory regulation or exceeds the permitted use, you will need to obtain permission directly from the copyright holder. To view a copy of this licence, visit http://creativecommons.org/licenses/by/4.0/.

\section{References}

Aczel J, Saaty T (1983) Procedures for synthesizing ratio judgments. J Math Psychol 27(1):93-102

Asia Pacific Coalition for School Safety (2017) Limiting and planning for schools as temporary evacuation centres in emergencies POLICY BRIEF AND PRACTICE GUIDANCE FOR PACIFIC NATIONS In support of the Worldwide Initiative for Safe Schools. Available at: https:/www.preventionweb.net/files /8196_Philippines.pdf

Association of Structural Engineers of the Philippines, Inc. (2015) National Structural Code of the Philippines, vol 1 Buildings, Towers and other Vertical Structures-NSCP 2015. Available at: https://archi ve.org/stream/NSCP2015/NSCP-2015_djvu.txt

Bernasconi M, Choirat C, Seri R (2014) Empirical properties of group preference aggregation methods employed in AHP: theory and evidence. Eur J Oper Res 232(3):584-592

Brunelli M (2015) Introduction to the Analytical Hierarchy Process.

CFE-DMHA (2018) Philippines Disaster Management Reference Handbook. Center for Excellence in Disaster Management \& Humanitarian Assistance, s.1.

Da Silva J (2007) Quality and standards in post-disaster shelter. The Institution of Structural Engineers.

Dall'Osso F et al (2009) A revised (PTVA) model for assessing the vulnerability of buildings to tsunami damage. Nat Hazards Earth Syst Sci 9:1557-1565

Faure Walker J, Crawford K (2017) Cash in a housing context: transitional shelter and recovery in Japan. Int J Disaster Risk Reduction 24:2212-4209. 
Felix D, Branco J, Feio A (2013) Temporary housing after disasters: a state of the art survey. Habitat Int 40:136-141

FEMA (2010) Guidance on planning for integration of functional needs support services in general population shelters, San Antonio, Texas

FEMA (2018) National engagement-planning considerations: evacuation and shelter-in-place. Available at: https://www.fema.gov/media-library-data/1533580334064-72e9356ed35b726b1a25f4a8c3372c9d/ DRAFT_Planning_Considerations_Evacuation_and_Shelter-in-Place_201808.pdf

Forman E, Peniwati K (1998) Aggregating individual judgments and priorities with the analytic hierarchy process. Eur J Oper Res 108(1):165-169.

Global Facility for Disaster Reduction and Recovery (GFDRR) (2011) Earthquake reconstruction. World Bank/GFDRR, Washington D.C.

HM Government (2014) Evacuation and shelter guidance, non-statutory guidance to complement Emergency preparedness and Emergency response and recovery, London, UK

Local Government of Cagayan de Oro City (2019) Comprehensive Land Use Plan 2019-2027. Available at: https://www.cagayandeoro.gov.ph/2016-07-25-02-34-58/comprehensive-development-plan-2

Luna E, Bautista M, De Guzman M (2008) MAINSTREAMING OF DISASTER RISK REDUCTION IN THE EDUCATION SECTOR IN THE PHILIPPINES

McPherson M, Counahan M, Hall J (2015) Responding to Typhoon Haiyan in the Philippines. Western Pacific Surveillance Response J 6(Supplement 1):1-101.

Nassirpour A, Galasso C, D’Ayala D (2017) SCOSSO: safer communities through Safer Schools. University College London, UK

National Institute for Educational Policy Research (2011) Available at: https://www.nier.go.jp/English/. Accessed 082019.

Naylor A., Faure Walker J, Suppasri A (2018) Suitability of the early warning systems and temporary housing for the elderly population in the immediacy and transitional recovery phase of the 2011 Great East Japan Earthquake and Tsunami. Int J Disaster Risk Reduction 31:302-310.

Orias P (2019) SunStar Cagayan de Oro. Available at: https://www.sunstar.com.ph/article/1824262.

Ramos R, de los Reyes V, Sucaldito M, Tayag E (2015) Rapid health assessments of evacuation centres in areas affected by Typhoon Haiyan. Western Pac Surveill Response J 6(Suppl 1):39-43. https://doi. org/10.5365/wpsar.2015.6.2.HYN_003

Rognerud E (2009) Experiences in post-disaster education recovery and school reconstruction: a case study for investment in "Soft Components".

Rohwerder B (2016) Transitional shelter in post-disaster contexts. GSDRC Helpdesk Research Report 1387.

Saaty R (1987) The analytical hierarchy process — what it is and how it is used. Math Model 9(3-5):161-176

Saaty T (1977) A scaling method for priorities in hierarchical structures. J Math Psychol 15(3):234-281.

Saaty T (1980) The analytical hierarchy process. McGraw-Hill, New York

Saaty T, Alsina C (1986) On synthesis of judgements. Socio-Econ Plan Sci 20(6):333-339

SCOSSO (2016) Safer Communities though Safer Schools. s.l., funded by the UK Engineering and Physical Sciences Research Council Global Challenges Research Fund.

Shaw R, Takeuchi Y (2012) East Japan Earthquake and Tsunami: key lessons for the education sector. Kyoto University, UNESCO Office Bangkok and Regional Bureau for Education in Asia and the Pacific, Japan.

Shaw R, Takeuchi Y, Fernandez G (2012) School recovery, Lessons from Asia.

Shaw R, Takeuchi YO (2012) East Japan earthquake and Tsunami: key lessons for the education sector. Available at: https://www.preventionweb.net/files/27138_03mrshaw.pdf

Sphere Association (2018) Sphere handbook: humanitarian charter and minimum standards in humanitarian response. Available at: https://spherestandards.org/wp-content/uploads/Sphere-Handbook-2018-EN. pdf]

Surmieda M et al (1992) Surveillance in evacuation camps after the eruption of Mt. Pinatubo, Philippines. Morbidity and Mortality Weekly Report: Surveillance Summaries, 28 08, 41(SS-4):9-12.

The Japan Times (2017) Only about 50\% of schools designated as shelters in times of disaster have emergency toilet facilities: survey. Available at: https://www.japantimes.co.jp/news/2017/08/29/national/50schools-designated-shelters-disaster-strikes-emergency-toilet-facilities/\#.XKXNfi2ZNGM. Accessed 082019.

The Sphere Project (2012) Humanitarian Charter and Minimum Standards in Humanitarian Response.

United Nations (2015) Sendai Framework for Disaster Risk Reduction 2015-2030. Available at: https:// www.preventionweb.net/files/43291_sendaiframeworkfordrren.pdf

Wang J (2016) Study on the context of school-based disaster management. International Journal of Disaster Risk Reduction Int J Disaster Risk Reduction 19:224-234 
WHO (1999) Rapid health assessment protocols for emergencies. Geneva, World Health Organization, 1999. Available at: https://www.wpro.who.int/vietnam/publications/rapid_health_assessment_proto cols.pdf. Accessed October 2019.

World Bank (2010) Disaster and emergency preparedness: guidance for schools (English). Available at: https://documents.worldbank.org/curated/en/141591468155378028/Disaster-and-emergency-prepa redness-guidance-for-schools. Accessed 2019

Yore R, Faure Walker J (2020) Early warning systems and evacuation: the rare and extreme hazard among frequent, small-scale events. Case Studies from the Philippines (Super Typhoon Yolanda (Haiyan)) and Dominica (Hurricane Maria). Disasters.

Publisher's Note Springer Nature remains neutral with regard to jurisdictional claims in published maps and institutional affiliations. 